Original Article

\title{
The effects of horse-riding simulator exercise and Kendall exercise on the forward head posture
}

\author{
Ki-Hyun Kim, PT, MS ${ }^{1)}$, Seong-Gil Kim, PT, PhD ${ }^{2)}$, Gak Hwangbo, PT, PhD ${ }^{3)^{*}}$ \\ 1) Department of Hippotheray Welfare, Sungduk College, Republic of Korea \\ 2) Department of Physical Therapy, Uiduk University, Republic of Korea \\ 3) Departmetn of Physical Therapy, College of Rehabilitation Science, Daegu University: 15 Jillyang, \\ Gyeongsan-si, Gyeongbuk 712-714, Republic of Korea
}

\begin{abstract}
Purpose] The aim of this study was to examine the effects of horse-riding simulator exercise and Kendall exercise on forward head posture. [Subjects and Methods] Thirty elderly college students with a forward head posture were randomly divided into two groups for 15 persons each, a horse-riding simulator group and Kendall exercise group, and performed exercise for eight weeks. [Results] The horse-riding simulator group and Kendall exercise group showed significant differences after the intervention in New York state posture rating, craniovertebral angle, and cranial rotation angle. The horse-riding simulator group showed a significantly smaller value than the Kendall exercise group for New York state posture rating evaluation after the intervention. [Conclusion] The results of this study indicate that horse-riding simulator exercise is more effective on forward head posture than Kendall exercise. Therefore, horse-riding simulator exercise can be used as a new simple treatment method for the ever-growing forward head posture.

Key words: Neck pain, Posture, Horse-riding simulator
\end{abstract}

(This article was submitted Oct. 21, 2014, and was accepted Dec. 11, 2014)

\section{INTRODUCTION}

People today frequently experience neck-related diseases due to simple repetitive jobs and incorrect posture resulting from industrialization. An incorrect posture causes stress on the neck structure, and continuous stress on the neck leads to FHP (forward head posture) accompanied by neck pain and headache ${ }^{1)}$. Major symptoms caused by FHP are abnormal scapula movement ${ }^{2}$, abnormality of the temporomandibular joint $^{3)}$, neck pain ${ }^{4-6)}$, pain in the interscapular band ${ }^{7)}$, and migraine, and it also causes problems such as decreased inhalation capacity and decreased maximum oxygen consumption and carbon dioxide discharge volume. Kendall exercise is generally used as physical therapy for FHP and induces proper neck alignment generally using strengthening methods for two muscles (deep cervical flexors and retractors of the scapula) and stretching methods for two muscles (neck extensor muscles and pectoralis) to help with FHP, which is a state of imbalance of muscles ${ }^{8}$. Normal Kendall exercise requires accurate movements but incorrect posture only has a bad influence on the spine. Unlike Kendall exercise, HRS (horse-riding simulator) exercise is a promising therapy generating interest as a means of accurately inproving posture

*Corresponding author. Gak Hwangbo (E-mail: hbgak@ daegu.ac.kr)

(C2015 The Society of Physical Therapy Science. Published by IPEC Inc. This is an open-access article distributed under the terms of the Creative Commons Attribution Non-Commercial No Derivatives (by-ncnd) License $<$ http://creativecommons.org/licenses/by-nc-nd/3.0/>. through horse riding 9 ).

Horse riding provides the rider with physical movements 500-1,000 times over the course of 10 minutes according to the horse's movement. The physical movements resulting from the horse's gait are a form of three-dimensional exercise (front and back, left and right, and up and down) and triggers the same exercise effect as human gait because they are similar to those of the human pelvis during gait. However, horse-riding therapy with a live horse has budgetary and spatial constraints that prevent its widespread use. Therefore, horse-riding exercise with a simulator, as a simple indoor treatment, can increase accessibility to this therapy and decrease its $\operatorname{cost}^{10)}$. The purpose of this study was to access the effect of HRS exercise, which has the advantages of horse-riding exercise, and Kendall exercise, which is a general treatment method for FHP, on postural alignment and spine alignment in FHP.

\section{SUBJECTS AND METHODS}

The study population was 30 college students with FHP randomly divided into two groups of 15 persons each, an HRS group and Kendall exercise group. The subjects performed exercise for 8 weeks; the selection criteria for the subjects were as follows: (1) mild or higher symptoms of FHP according to the New York State Posture Rating Chart (Harman et al., 2005); (2) CVA (craniovertebral angle) less than $53^{\circ}$; (3) no orthopedic disease that might affect testing; and (4) no visual impairment, visual field defect, or mental or perceptional problem that might affect testing. All subjects understood the purpose of this study and provided informed 
consent in writing prior to participation in the study in accordance with the ethical principles of the Declaration of Helsinki (Table 1).

The horse-riding group and Kendall group exercised 30 minutes per each round three times a week for 8 weeks.

A horse-riding simulator is a machine that creates movements similar to a horse, and an indoor HRS (Honjin, Korea), was used in this study. The Kendall exercise group participated in 5 sets of consisting of 12 repetitions of postures, each taking 30 seconds, based on Kendall exercise ${ }^{5,11)}$. The Kendall exercise methods were as follows: (1) Strengthening the deep cervical flexors, lying flat on the back with the chin down and then lifting the head and holding this position for 2-8 seconds to strengthen deep cervical flexors; (2) Stretching the cervical extensors, placing both hands on the occipital area in a sitting position followed by a flexed neck posture with the head down to stretch the cervical extensors; (3) strengthening shoulder retraction, putting a TheraBand around a secure object and pulling the band back with both hands as far as possible to move the shoulder blades toward each other in a standing position; and (4) stretching the pectoralis muscle, placing both hands on theoccipital area and pulling the elbows back up (bilateral) and performing arm abduction and external rotation (unilateral).

The NSPR (New York State posture rating), CVA, and CRA (cranial rotation angle) were evaluated to assess joint angle in FHP. A weight was hung from the ceiling on a string and kept perpendicular to the floor, forming a plumb line. Marks were attached to the areas of the 7 th cervical vertebra, auricular tragus, and acromion when each subject reached the NHP (neutral head position). Each subject was photographed in a standing position 3 times ${ }^{5,6,11)}$.

This study used SPSS for Windows (version 20.0) to

Table 1. General characteristics of subjects

\begin{tabular}{lcc}
\hline & HRS group & $\begin{array}{c}\text { Kendall exercise } \\
\text { group }\end{array}$ \\
\hline Gender (M/F) & $8 / 7$ & $7 / 8$ \\
Age (years) & $19.9 \pm 1.0$ & $20.5 \pm 1.2$ \\
Height $(\mathrm{cm})$ & $166.1 \pm 9.3$ & $168.8 \pm 10.4$ \\
Weight $(\mathrm{kg})$ & $61.4 \pm 14.5$ & $63.5 \pm 12.0$ \\
\hline
\end{tabular}

Mean \pm SD. HRS: horse-riding simulator analyze the data. The paired t-test was used to compare the effect between before and after the intervention, and the independent $t$-test was used to compare the results between the two groups. The statistical significance level was set at $\alpha=0.05$.

\section{RESULTS}

Comparison between before and after the intervention revealed that the HRS group and Kendall exercise group showed significant differences after the intervention in NSPR, CVA, and CRA $(\mathrm{p}<0.05)$.

Comparison between the two groups revealed no significant difference between the groups in NSPR, CVA, and CRA before the intervention $(p>0.05)$. However, the HRS group showed a significantly smaller NSPR value than the Kendall exercise group after the intervention $(\mathrm{p}<0.05)$ (Table 2$)$.

\section{DISCUSSION}

These days, many people experience FHP due to increased computer use caused by advances in science, technology, and industrialization and suffer from musculoskeletal abnormalities and pain caused by FHP ${ }^{12}$. The physical therapy methods that have been used to cure FHP and to correct posture are preservation therapies, such as thermotherapy, electrical stimulation therapy, and traction therapy, and therapeutic exercise, such as McKenzie's posture exercise and Kendall's muscle strengthening and stretching exercise ${ }^{5)}$.

Recently, horse-riding exercise is being focused on as a new treatment method inducing a correct posture through use of the irregular movements of horse riding. Particularly, HRS can be simply applied without spatial constraint. Therefore, Kendall exercise, the conventional method, and HRS exercise, the new method, were comparatively analyzed to assess the effect of HRS exercise on FHP correction and posture. Previous research showed that horse-riding exercise in children with cerebral palsy improved weight shifting and postural control and especially decreased neck hyperextension through enhanced midline head control $^{13-15)}$. In the postural alignment evaluation in the present study, NSPR decreased, CVA increased, and CRA decreased the HRS exercise. These results are consistent with the outcomes in previous research, and HRS exercise is considered to have a positive influence on FHP.

Table 2. Comparison of neck alignment for each group

\begin{tabular}{|c|c|c|c|c|}
\hline Variable & & Group & Pre & Post \\
\hline \multirow{6}{*}{$\begin{array}{l}\text { Neck } \\
\text { alignment }\end{array}$} & \multirow{2}{*}{ NSPR (cm) } & HRS & $3.6 \pm 0.9$ & $2.2 \pm 1.2^{\mathrm{ab}}$ \\
\hline & & Kendall & $3.80 \pm 1.0$ & $3.33 \pm 1.1^{\mathrm{ab}}$ \\
\hline & \multirow{2}{*}{$\operatorname{CVA}\left({ }^{\circ}\right)$} & HRS & $49.9 \pm 2.3$ & $53.2 \pm 3.6^{\mathrm{a}}$ \\
\hline & & Kendall & $49.3 \pm 2.2$ & $51.2 \pm 1.7^{\mathrm{a}}$ \\
\hline & \multirow{2}{*}{ CRA $\left({ }^{\circ}\right)$} & HRS & $144.2 \pm 4.9$ & $139.9 \pm 4.1^{\mathrm{a}}$ \\
\hline & & Kendall & $146.8 \pm 7.1$ & $142.8 \pm 7.1^{\mathrm{a}}$ \\
\hline
\end{tabular}

${ }^{*} p<0.05$. Mean \pm SD, NSPR: New York State posture rating, CVA: craniovertebral angle; CRA: cranial rotation angle; HRS: horse-riding stimulation. asignificant difference between pre- and post-intervention values, ${ }^{b}$ significant difference between the groups 
Kendall exercise is a stretching method used to strengthen cervical muscles and is frequently used for improvement of neck stability and postural control, for which it has been proven to be effective ${ }^{5,16)}$. The Kendall exercise group showed a decreased NSPR, increased CVA, and decreased CRA, which indicate improvement of neck stability. However, there were statistically significant differences between the Kendall group and HRS group after the intervention. These results show that HRS exercise is more effective on FHP than Kendall exercise. Therefore, the HRS can be a new simple treatment method for the ever-growing FHP. A limitation of this study is that representativeness could not be guaranteed because of small number of subjects. The duration of improved posture from Kendall exercise and HRS exercise should be evaluated through follow-up testing.

\section{REFERENCES}

1) Hickey ER, Rondeau MJ, Corrente JR, et al.: Reliability of the cervica range of motion (CROM) device and plumb-line techniques in measuring resting head posture (RHP). J Manual Manip Ther, 2000, 8: 10-17. [CrossRef]

2) Weon JH, Oh JS, Cynn HS, et al.: Influence of forward head posture on scapular upward rotators during isometric shoulder flexion. J Bodyw Mov Ther, 2010, 14: 367-374. [Medline] [CrossRef]

3) Sonnesen L, Bakke M, Solow B: Temporomandibular disorders in relation to craniofacial dimensions, head posture and bite force in children selected for orthodontic treatment. Eur J Orthod, 2001, 23: 179-192. [Medline] [CrossRef]

4) Yip CH, Chiu TT, Poon AT: The relationship between head posture and severity and disability of patients with neck pain. Man Ther, 2008, 13 148-154. [Medline] [CrossRef]

5) Harman K, Hubley-Kozey CL, Butler H: Effectiveness of an exercise pro- gram to improve forward head posture in normal adults: a randomized, controlled 10-week trial. J Manual Manip Ther, 2005, 13: 163-176. [CrossRef]

6) Garrett TR, Youdas JW, Madson TJ: Reliability of measuring forward head posture in a clinical setting. J Orthop Sports Phys Ther, 1993, 17: 155-160. [Medline] [CrossRef]

7) Griegel-Morris P, Larson K, Mueller-Klaus K, et al.: Incidence of common postural abnormalities in the cervical, shoulder, and thoracic regions and their association with pain in two age groups of healthy subjects. Phys Ther, 1992, 72: 425-431. [Medline]

8) Kendall FP, McCreary EK, Provance PG, et al.: Muscles, testing and function, with posture and pain. Philadelphia: Lippin Cott William \& Wilkins, 1993.

9) Granados AC, Agís IF: Why children with special needs feel better with hippotherapy sessions: a conceptual review. J Altern Complement Med, 2011, 17: 191-197. [Medline] [CrossRef]

10) Kim S, Yuk GC, Gak H: Effects of the horse riding simulator and ball exercises on balance of the elderly. J Phys Ther Sci, 2013, 25: 1425-1428. [Medline] [CrossRef]

11) Diab AA, Moustafa IM: The efficacy of forward head correction on nerve root function and pain in cervical spondylotic radiculopathy: a randomized trial. Clin Rehabil, 2012, 26: 351-361. [Medline] [CrossRef]

12) Mekhora $K$, Liston $C$, Nanthavanij $S$, et al.: The effect of ergonomic intervention on discomfort in computer users with tension neck syndrome. Int $\mathrm{J}$ Ind Ergon, 2000, 26: 367-379. [CrossRef]

13) Bertoti DB: Effect of therapeutic horseback riding on posture in children with cerebral palsy. Phys Ther, 1988, 68: 1505-1512. [Medline]

14) Lee DR, Lee NG, Cha HJ, et al.: The effect of robo-horseback riding therapy on spinal alignment and associated muscle size in MRI for a child with neuromuscular scoliosis: an experimenter-blind study. NeuroRehabilitation, 2011, 29: 23-27. [Medline]

15) Shurtleff TL, Standeven JW, Engsberg JR: Changes in dynamic trunk/ head stability and functional reach after hippotherapy. Arch Phys Med Rehabil, 2009, 90: 1185-1195. [Medline] [CrossRef]

16) Diab AA: The role of forward head correction in management of adolescent idiopathic scoliotic patients: a randomized controlled trial. Clin Rehabil, 2012, 26: 1123-1132. [Medline] [CrossRef] 